\title{
ANALYSIS OF SPALLATION BASED UPON STATISTICAL MICRODAMAGE MECHANICS*
}

\author{
WENSHENG HAN, LETIAN SHEN and YILONG BAI \\ Laboratory for Non-Linear Mechanics of Continuous Media, \\ Institute of Mechanics, Chinese Academy of Sciences, \\ Beijing 100080, China
}

(Received 15 July1994; in revised form 10 November 1994, 11 May 1995 and 23 February 1996)

\begin{abstract}
Summary - A relationship between the cumulative length of microcracks and the amplitude and duration of tensile impulse in spallation was established based on the application of statistical microdamage mechanics, which included a statistical formulation and dynamic laws of microdamage under loading. Since the degrees of spallation, called incipient, intermediate and complete spallation, can be characterized by the cumulative length of microcracks, a physical interpretation of an empirical criterion to spallation was presented. (C 1997 Elsevier Science Ltd.
\end{abstract}

Keywords: statistical microdamage mechanics, spallation, criterion

\section{INTRODUCTION}

In 1910 B. Hopkinson reported for the first time that spallation was caused by a tensile stress wave resulting from the reflection of compression waves at the interfaces adjacent to low impedance media[1]. Since then, the critical conditions for spallation, i.e. spallation criteria, have been proposed and studied by many researchers. First, the strength criterion of spallation was suggested[2]. That is, spallation will occur if

$$
\sigma \geq \sigma_{\mathrm{c}}
$$

where $\sigma$ is the tensile stress and $\sigma_{\mathrm{c}}$ is the dynamic strength of a material. It is obvious that the strength theory of spallation is the extension of the static strength theory of materials. However, many experiments have demonstrated that the spallation strength of materials varies with the tensile impulse duration, while the static strength of materials is usually of constant value no matter what kind of loading is applied [3]. Usually, spall fracture is classified into several stages according to the damage level, which is indicated roughly by terms such as "initial", "intermediate" or "complete". The complete spallation refers to the complete separation of the material whereas the initial and intermediate spallation indicate cracking of a few isolated grains and partial separation of the material respectively.

Butcher et al. [4] revealed that spallation was a time-dependent process, which marked the birth of the cumulative damage theory of spallation, i.e. that nucleation, growth, and coalescence of microdamage constituted a spallation process[4]. Thus, the difference between the spall fracture and the quasistatic fracture "arises because, while the impulsive load is usually of sufficient intensity to nucleate a large number of cracks, the duration of its application is too short to permit propagation of individual cracks over large areas"[5]. Hence, the spall fracture depends on the duration of the stress wave. There are two approaches to the study of spallation. One is the establishment of an empirical spallation criterion which determines whether or not spall (i.e. some preselected spall level) will occur under given experimental conditions. The other is to describe the spall damage development with a continuous field variable[6]. The latter one introduced the concept of continuous damage as a replacement for the discrete description of spall and generalized the spall criteria to continuous measures of spall. This method is entirely phenomenological even though it is effective and the literature on it is not only very extensive but also growing at an ever increasing rate. Therefore, micromechanical studies of spall damage of materials to evaluate the continuous theory of spall

\footnotetext{
* The project was supported by the National Natural Science Foundation of China.
} 
damage are badly wanted. Curran et al.[7] have investigated the spall failure of materials and suggested a method which is composed of the statistical descriptions and microscopic dynamic laws of microdamage; they refer to their approach as "microstatistical fracture mechanics"[7]. This microstatistical approach connected the spall fracture with the micromechanical development of spall damage directly and hence had a firmly physical basis. However, a spallation criterion based on this approach has not been given. In this paper, we try to give some tentative results in this area. In Section 2 , we introduce an empirical criterion for spallation based on the ideas of Butcher $e t$ al. [4] and some definitions of damage functions for characterizing the spall levels. Section 3 gives the relationship between the criterion and the process of spallation based on the concepts of statistical microdamage mechanics, and in Section 4 the evaluation of spallation criteria with the experiments and discussions on the results are given. Some preliminary conclusions are presented in Section 5.

\section{CUMULATIVE DAMAGE CRITERION}

According to the cumulative damage theory of spallation, Tuler[8] and Butcher et al.[4] proposed a general spallation criterion which can be written as:

$$
\int_{T, n}^{t}\left(\sigma-\sigma_{0}\right)^{\prime} d t=K
$$

where $\sigma$ is the tensile stress, the duration of tensile stress is from $T_{0}$ to $T, \sigma_{0}$ is the threshold stress for spallation and $\lambda$ and $K$ are fitted parameters. Shen et al.[9] indicated that $\sigma$ can be regarded as the amplitude of a square impluse in normal plate impact. Therefore, Eqn (2) can be rewritten as:

$$
\left(\sigma / \sigma_{0}, 1\right) \Delta T=K^{\prime}
$$

where $i$ and $K^{\prime}$ are fitted parameters and $\Delta T$ is the duration of tensile stress.

Generally, one can use Eqn (2) or (3) to deduce a spall criterion for the preselected amount of spall damage. So, a damage variable must be well defined firstly to properly characterize the degrees of spallation. A series of plate impact tests to establish the spallation criterion for an aluminium alloy were conducted with a light gas gun. The specimens were taken from a rolled sheet of an aluminium alloy similar to 2219-T6 Al. The physical and mechanical properties of the material are shown in Table 1.

The details of experiments were presented in Ref. [9]. Fig. 1 shows that paralleled microcracks occurred in the metallographic section of an incipient spalled specimen. Figures 2-3 are metallographic sections of spalled specimens for different $F_{1}$ values. In fact these microcracks were cut from penny-shaped microcracks inside materials. Shen et al. [9] defined two kinds of damage functions to characterize the degrees of spall. One is

$$
F_{1}=1-\frac{\sigma_{\mathrm{r}}}{\sigma_{\mathrm{b}}}
$$

where $\sigma_{r}$ is the experimentally determined residual ultimate tensile strength of a certain degree of spalled specimen and $\sigma_{\mathrm{b}}$ is the ultimate tensile strength of undamaged aluminium alloy. The other is

$$
F_{2}=\frac{l}{l}
$$

Table 1. The physical and mechanical properties of the aluminium alloy

\begin{tabular}{lr}
\hline Density & $2.83 \mathrm{~g} / \mathrm{cm}^{3}$ \\
Tensile yield strength & $333 \mathrm{MPa}$ \\
Tensile ultimate strength & $449 \mathrm{MPa}$ \\
Elastic modulus & $81 \mathrm{GPa}$ \\
Speed of sound & $5827 \mathrm{~m} \mathrm{~s}$
\end{tabular}




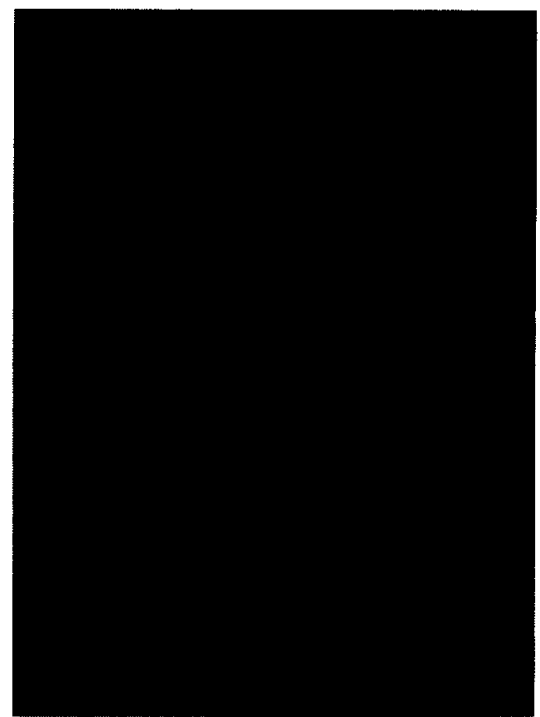

Fig. 1. Microcracks formed in specimen under impact loading

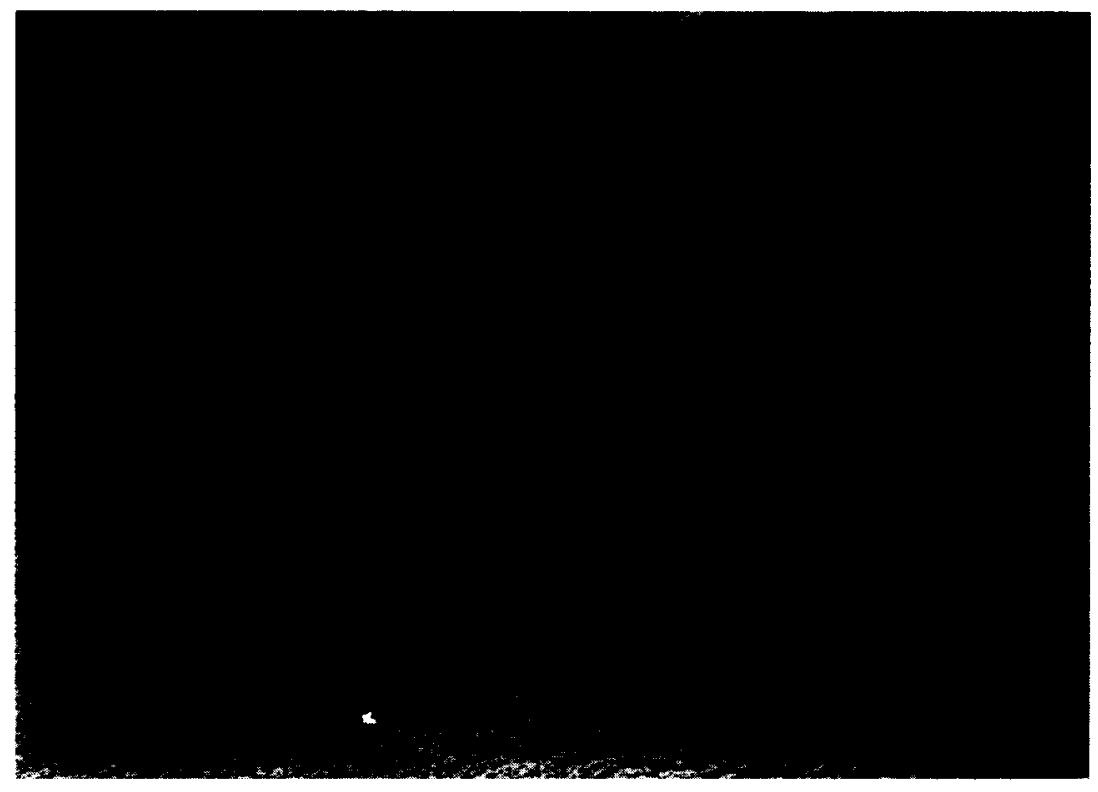

Fig. 2. Crack feature of specimen with $F=1 / 3$ magnification $\times 50$

where $l$ is the total length of cracks in a certain section of a specimen and $l$ is total length of this section (see Figs. 2\&3).

The measurements showed that there was a one-to-one correspondence of two above damage functions. Fig. 4 shows the measured results. It should be noted that $F_{1}$ is a mechanical and macroscopic quantity and $F_{2}$ is a geometrical and microscopic quantity. Hence, the geometrical damage function, $F_{2}$, is also a fairly good representation of spall levels.

The fitted spallation criteria from the experimental data in the form of Eqn (3) were :

$$
\begin{gathered}
(\sigma / 450-1)^{1.171} \Delta T=1.798 \\
(\sigma / 450-1)^{1.381} \Delta T=2.438 \\
(\sigma / 450-1)^{1.795} \Delta T=3.853
\end{gathered}
$$

$$
\begin{gathered}
\text { for } F_{1}=1 / 3 \\
\text { for } F_{1}=1 / 2 \\
\text { for } F_{1}=1
\end{gathered}
$$




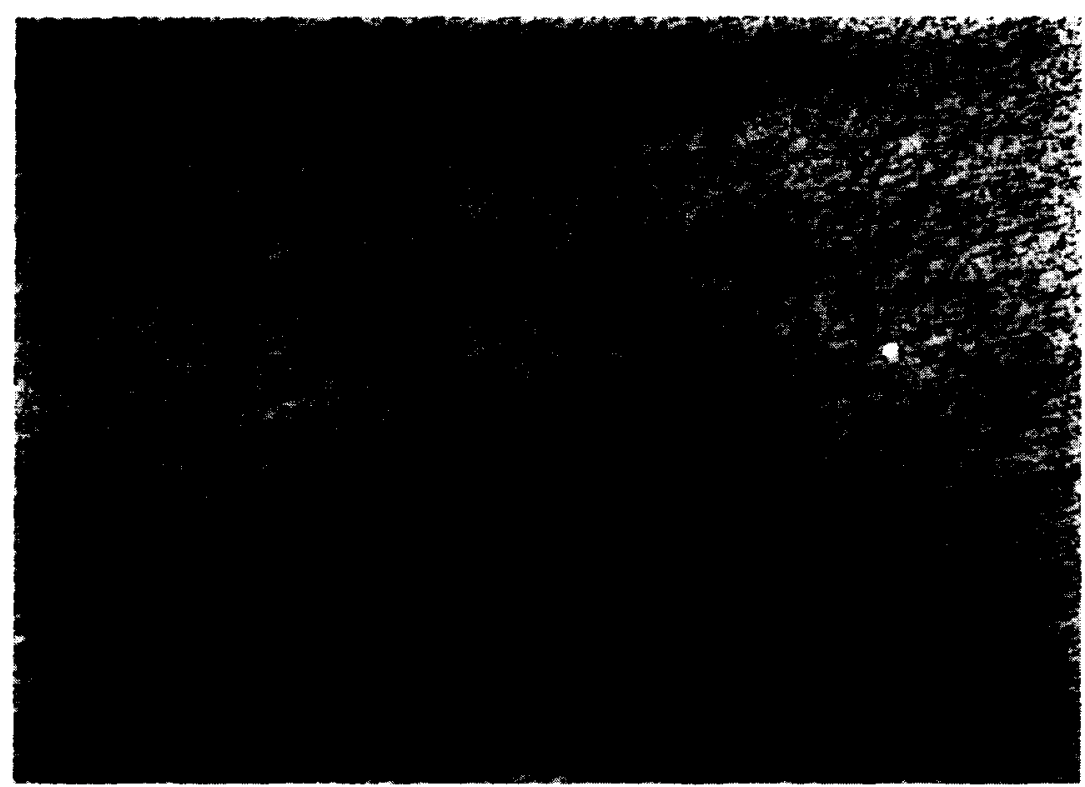

Fig. 3. Crack feature of specimen with $F=12$ magnification $\times 50$

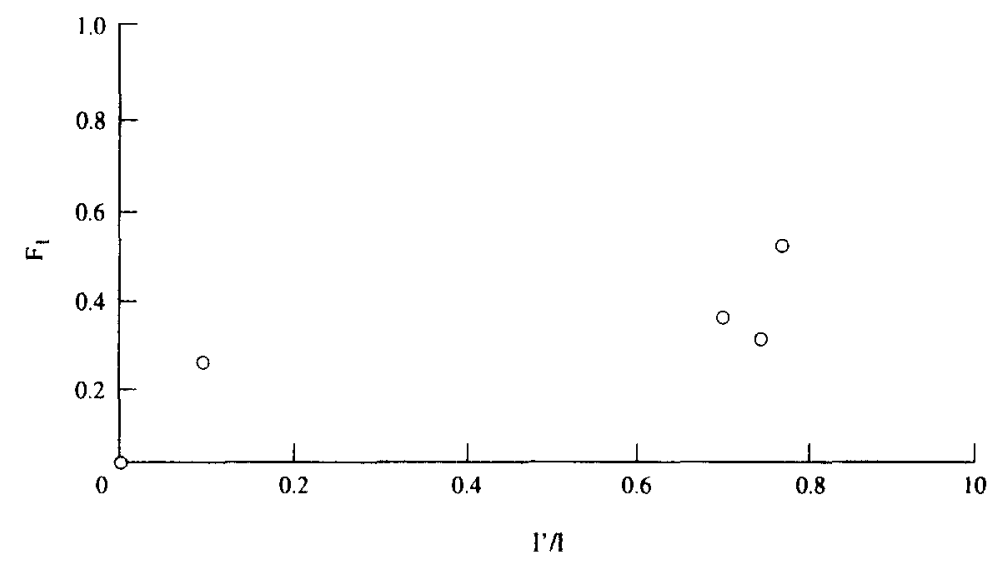

Fig. 4.

Therefore, the spallation criterion for the aluminium alloy for different degrees of spallation becomes

$$
(\sigma / 450-1)^{n\left(F_{1}\right)} \Delta T=K\left(F_{1}\right) .
$$

Shen et al. [9] indicated that $K$ should be a measure of the necessary time for the corresponding damage level from dimensional analysis. However, the implication of the variation of $n$ with $F$, was not clarified. Clearly, the appropriate physical basis of the above empirical criterion is required.

\section{AN INTERPRETATION BASED UPON STATISTICAL MICRODAMAGE MECHANICS}

Now we define a new damage function from the above mentioned experimental results (see Figs. 2-3) as

$$
F_{3}=\int_{0}^{\prime} c^{\prime} \cdot m\left(c^{\prime}\right) \mathrm{d} c^{\prime}
$$


where $m\left(c^{\prime}\right)$ is the number density distribution of microcracks in sectional surface of the plate target, i.e. $m\left(c^{\prime}\right) \mathrm{d} c^{\prime}$ is total number of microcracks with apparent sizes between $c^{\prime}-c^{\prime}+\mathrm{d} c^{\prime}$ per unit area. So, this damage function is the sum of length of total microcracks per unit area in sectional surface. It should be noted that $F_{3}$ gives the cumulative crack length per unit sectional area whereas $F_{2}$ gives length of cracks divided by section length. In fact, the measurements of $F_{2}$ should be accomplished in certain width of heavily damage regions. Therefore, $F_{3}$ could be interpreted as $F_{2}$ divided by this width. In this sense, it is appropriate to use $F_{3}$ to characterize the spall levels as well as $F_{2}$.

Next, we try to connect the damage function $F_{3}$ with the micromechanical laws such as the nucleation rate and growth rate of microcracks. The details of the testing procedure to derive the nucleation rate and growth rate of microcracks were given in Refs [9] and [10]. Figure 5 shows the number density of nucleation microcracks under different stresses. The fitted nucleation rate by use of the exponential form given by Curran et al. [7] is

$$
\dot{N}=\dot{N}_{0} \exp \left[\left(\sigma-\sigma_{0}\right) / \sigma_{1}\right]
$$

where $\dot{N}$ is the nucleation rate of microcracks, i.e. the number of nucleated microcracks per unit time per unit physical volume of the body, $\dot{N}_{0}$ is the threshold nucleation rate, $\sigma$ is the amplitude of tensile wave, and $\sigma_{0}$ and $\sigma_{1}$ are material properties. The fitted values of the parameters in Eqn (11) with the experimental data of Shen et al. [9] are

$$
\begin{gathered}
\dot{N}_{0}=1.43 \times 10^{4} / \mu \mathrm{s} \cdot \mathrm{mm}^{3} \\
\sigma_{0}=4.5 \times 10^{2} \mathrm{MPa} \\
\sigma_{1}=6.0 \times 10^{2} \mathrm{MPa}
\end{gathered}
$$

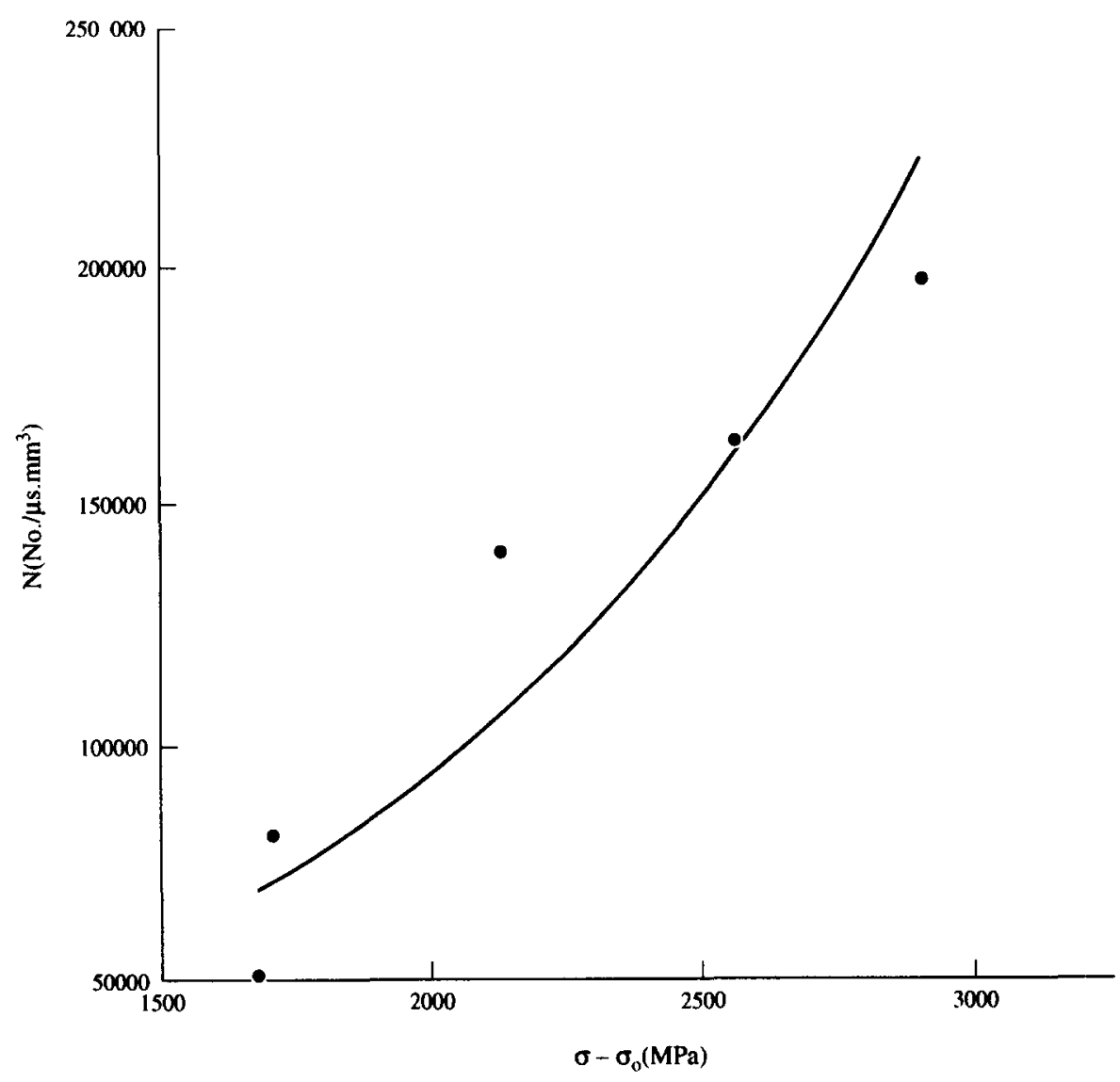

Fig. 5. 
The growth rate of microcracks of the aluminium alloy was given in Ref. [10] by a new statistical approach and confirmed to be a viscous growth as Curran et al. [7] have revealed under impact loading,

$$
A(c)=\frac{\sigma-\sigma_{0}}{4 \eta} c
$$

where $A(c)$ is the growth rate of microcracks with size $c$ in the physical volume, and $\sigma_{0}$ is the threshold stress for the growth of microcracks which is the same as that of the nucleation threshold stress in this case. $\eta$ is a viscous parameter approximately $1.5 \times 10^{3} \mathrm{~Pa} \cdot \mathrm{s}$ [11].

It is worth noting that the sizes $c$ and $c^{\prime}$ are different. The $c$ is the true size of microcracks, for example, the true diameter of sphere or penny-shaped cracks; $c^{\prime}$ is apparent size of microcracks on sectional surface, i.e. the diameter of the apparent circle of sphere or the length of the apparent crack line of penny-shaped crack, which are sectioned and show themselves as circles or crack lines with size $c^{\prime}$ on the sectional surface.

For connecting the damage function $F_{3}$, the sum of length of total microcracks in a sectional surface of a spalled specimen per unit area, with the micromechanical laws of microcracks inside materials, the statistical transformation from the sectional number density distribution $m\left(c^{\prime}\right)$ to the volumetrical number density distribution of microcracks $n(c)$ should be completed first. This can be done with the transformation governing equation given by Bai et al. [12] (see appendix A) either for spherical voids or penny-shaped cracks all lying in the same orientation (paralleled microcracks as showed in Fig. 1)

$$
\frac{m\left(c^{\prime}\right)}{c^{\prime}}=\int_{c^{\prime}} n(c) \frac{\mathrm{d} c}{\sqrt{c^{2}-c^{\prime 2}}}
$$

where $n(c) \mathrm{d} c$ is the total number of microcracks with sizes $c-c+\mathrm{d} c$ per unit physical volume of the body. The solution of the integral equation was obtained by partly integrating Ref. [12] (see appendix B)

$$
n(c)=\frac{2}{\pi} \int^{\prime} \frac{c}{\sqrt{c^{\prime 2}-c^{2}}}\left[-\frac{1}{c^{\prime}} \frac{\mathrm{d} m\left(c^{\prime}\right)}{\mathrm{d} c^{\prime}}+\frac{m\left(c^{\prime}\right)}{c^{\prime 2}}\right] \mathrm{d} c^{\prime}
$$

the apparent boundary condition, $m(x)=0$, was used in the derivation.

Curran and his co-workers [7] started the important work about the statistical evolution of microcracks and its effect on mechanical properties of damaged materials based on the empirical statistics of microdamage [7]. Bai et al. [12] have put forward a governing equation of the statistical evolution of microcracks other than the empirical statistics [13]. The governing equation of microcracks can be written

$$
\frac{\partial n}{\partial t}+\frac{\partial(n A)}{\partial c}=n_{N}
$$

where $\partial n / \partial t$ is just the increasing number per unit time, holding $c$ fixed, and $\partial(n A) / \partial c$ is the rate by which cracks are converted from one size to another. $\mathrm{n}_{N}$ is the nucleation rate of microcracks, i.e. $\mathrm{n}_{N} \mathrm{~d} c$ is the number of nucleation microcracks per unit time per unit physical volume.

The measurements showed that the number density distribution of microcracks in sectional surface of the specimen, $m\left(c^{\prime}\right)$, is the Rayleigh distribution [14]:

$$
m\left(c^{\prime}\right)=A_{0}\left(\frac{c^{\prime}}{x}\right) e^{(c / x)^{2}}
$$


where $A_{0}=2 \int_{0}^{\infty} m\left(c^{\prime}\right) \mathrm{d} c^{\prime} / \alpha$ is a normalized parameter of the distribution and $\alpha$ is a characteristic parameter of the distribution. The measurements also showed the variation of $\alpha$ was a little in the evolution of spalled damage in the aluminium alloy while $A_{0}$ increased with increasing damage $[10]$.

The solution (14) shows the volumetric distribution of $n(c)$ to be Rayleigh distribution too, i.e.

$$
n(c)=\frac{2}{\sqrt{\pi}} \frac{1}{\alpha} m(c) \text {. }
$$

So, in this case the sectional size distribution is a nice representation of its volumetric counterpart. In the light of Eqn (17), the damage function in sectional surface, $F_{3}$, can be written as

$$
F_{3}=\alpha \frac{\sqrt{\pi}}{2} \int_{0}^{\infty} c \cdot n(c) \mathrm{d} c .
$$

Let

$$
L=\int_{0}^{\infty} c \cdot n \mathrm{~d} c
$$

Eqn (18) can be rewritten as

$$
F_{3}=\alpha \frac{\sqrt{\pi}}{2} L
$$

Therefore, the cumulative length of microcracks per physical volume is also a good damage function for characterizing the degrees of spallation. Thus, let us investigate the damage function $L$. The rate of damage function $L$ is

$$
\dot{L}=\frac{\partial}{\partial t}\left[\int_{0}^{\infty} c \cdot n \mathrm{~d} c\right]=\int_{0}^{\infty} c \cdot \frac{\partial n}{\partial t} d c
$$

because the conservation Eqn (15) can be rewritten as

$$
\frac{\partial n}{\partial t}=n_{N}-\frac{\partial(A n)}{\partial c}
$$

Due to substitution of Eqn (22) into Eqn (21), the rate of damage function can be derived as

$$
\dot{L}=\int_{0}^{\infty} c \cdot n_{N} \mathrm{~d} c+\int_{0}^{\infty} n \cdot A \mathrm{~d} c-\left.c \cdot A \cdot n\right|_{0} ^{\infty} .
$$

We notice

$$
\int_{0}^{\infty} c \cdot n_{N} \mathrm{~d} c=c_{0} \int_{0}^{\infty} n_{N} \mathrm{~d} c=c_{0} \cdot \dot{N}=c_{0} \dot{N}_{0} \exp \left(\frac{\sigma-\sigma_{0}}{\sigma_{1}}\right)
$$

where $c_{0}$ is average nucleation size of microcracks. Concerning Eqns (16) and (17), the last term in the right hand side of Eqn (23) vanishes. The evolution rate of microcracks $\dot{L}$ can be obtained as follows

$$
\dot{L}=c_{0} \dot{N}_{0} \exp \left(\frac{\sigma-\sigma_{0}}{\sigma_{1}}\right)+\frac{\sigma-\sigma_{0}}{4 \eta} L
$$

Suppose that the tensile wave $\sigma$ in normal planar impact is applied to an undamaged material at initial time $t=0$, i.e.

$$
L(\sigma, t)=0, \quad \text { when } t=0
$$


then, the solution to Eqn (25) was derived as

$$
L=4 \eta c_{0} \dot{N}_{0} \frac{1}{\sigma-\sigma_{0}} \exp \left(\frac{\sigma-\sigma_{0}}{\sigma_{1}}\right)\left[\exp \left(\frac{\sigma-\sigma_{0}}{4 \eta} t\right)-1\right] .
$$

The graph of this function is plotted in Fig. 6. It is clear that the accumulated length of microcracks rises faster as the tensile stress and its duration increase, and the surface could be approximated by the planar surface at an initial time under low tensile loading. It indicates that at the initial development of spallation the accumulated damage varies linearly with time.

It is evident that the degrees of spallation can be characterized properly by the accumulated length of microcracks, i.e. the damage function $L$. Hence, Eqn (26) can be used as a criterion for continuous measure of spallation. For a preselected level of spallation $L$, the required amplitude $\sigma$ and duration $t$ of a tensile wave can be derived with Eqn (26). In the next section, Eqn (26) will be evaluated by the experimental data of Shen et al. [9] and the comparison between the criteria Eqn (26) of this paper and the criteria of Shen et al. [Eqn (9)] was given and discussed.

\section{EXPERIMENTAL EVALUATION AND DISCUSSION}

The details of the experiments of planar impact on the aluminium alloy can be found in Shen et al. [9] Tables 2-4 show the experimental data for three different groups $\left(F_{l}=1 / 3,1 / 2\right.$ and 1$)$.

For the spalled aluminium alloy, the measurements give the parameters in Eqn (26) are as follows:

$$
\begin{gathered}
c_{0}=3.4 \mu \mathrm{m} \\
\dot{N}_{0}=1.43 \times 10^{4} / \mu \mathrm{s} \cdot \mathrm{mm}^{3} \\
\eta=1.5 \times 10^{3} \mathrm{~Pa} \cdot \mathrm{s} \\
\sigma_{1}=600 \mathrm{MPa} \\
\sigma_{0}=450 \mathrm{MPa} .
\end{gathered}
$$

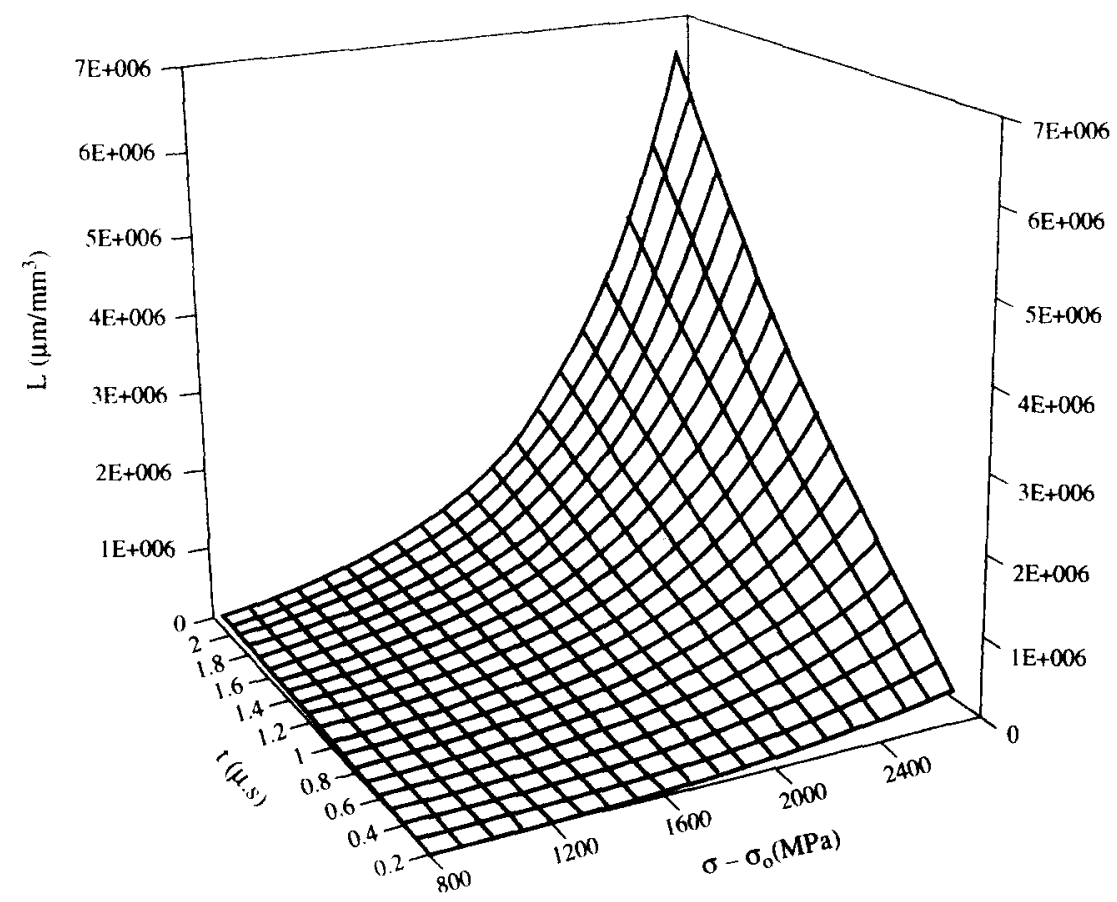


Table 2. Experimental Results of Group 1, for $F_{1}=1 / 3$

\begin{tabular}{|c|c|c|c|c|c|c|c|c|c|}
\hline Test No. & $\begin{array}{c}\text { Impact } \\
\text { velocity } \\
V_{1} \\
(\mathrm{~m} / \mathrm{s})\end{array}$ & $\begin{array}{l}\text { Thickness } \\
\text { of speci- } \\
\text { men }(\mathrm{mm}) \\
\text { Flyer }\end{array}$ & Target & $\begin{array}{l}\text { Duration } \\
\text { of } \sigma \\
\qquad T \\
(\mu \mathrm{s})\end{array}$ & $\begin{array}{l}\text { Experimental } \\
\text { results }\end{array}$ & $\begin{array}{l}\text { Nominal te } \\
\sigma(\mathrm{MPa}) \\
\text { Prediction } \\
\text { Eqn }[6]\end{array}$ & $\begin{array}{l}\text { sile stress } \\
\text { Error } \\
(\%)\end{array}$ & $\begin{array}{l}\text { Prediction } \\
\text { Eqn [26] }\end{array}$ & $\begin{array}{l}\text { Error } \\
(\%)\end{array}$ \\
\hline $84-98$ & 108.9 & 5.03 & 10.08 & 1.741 & 914 & 913 & 0.13 & 912 & 0.22 \\
\hline $84-71$ & 122.4 & 4.02 & 8.06 & 1.393 & 1029 & 1010 & 1.90 & 1043 & 1.36 \\
\hline $84-62$ & 160.6 & 2.40 & 5.00 & 0.835 & 1359 & 1316 & 3.12 & 1355 & 0.29 \\
\hline $84-88$ & 176.9 & 1.92 & 3.94 & 0.669 & 1500 & 1497 & 0.21 & 1491 & 0.60 \\
\hline
\end{tabular}

Table 3. Experimental Results of Group 2, for $F_{1}=1 / 2$

\begin{tabular}{|c|c|c|c|c|c|c|c|c|c|}
\hline Test No. & $\begin{array}{l}\text { Impact } \\
\text { velocity } \\
V_{1} \\
(\mathrm{~m} / \mathrm{s})\end{array}$ & $\begin{array}{l}\text { Thickness of } \\
\text { specimen } \\
(\mathrm{mm}) \\
\text { Flyer }\end{array}$ & Target & $\begin{array}{l}\text { Duration } \\
\text { of } \sigma \\
\quad \Delta T \\
(\mu \mathrm{s})\end{array}$ & $\begin{array}{l}\text { Experimental } \\
\text { results }\end{array}$ & $\begin{array}{l}\text { Nominal te } \\
\sigma(\mathrm{MPa}) \\
\text { Prediction } \\
\text { Eqn [6] }\end{array}$ & $\begin{array}{l}\text { nsile stres } \\
\text { Error } \\
(\%)\end{array}$ & $\begin{array}{l}\text { Prediction } \\
\text { Eqn [26] }\end{array}$ & $\begin{array}{l}\text { Error } \\
(\%)\end{array}$ \\
\hline $84-13$ & 122.2 & 5.00 & 10.00 & 1.733 & 1028 & 1026 & 0.13 & 1027 & 0.10 \\
\hline $84-70$ & 139.3 & 4.04 & 8.04 & 1.358 & 1146 & 1137 & 0.76 & 1174 & 2.44 \\
\hline $84-10$ & 176.1 & 2.46 & 4.96 & 0.856 & 1494 & 1410 & 5.58 & 1457 & 2.48 \\
\hline $84-90$ & 187.4 & 1.94 & 3.94 & 0.676 & 1592 & 1589 & 0.18 & 1603 & 0.69 \\
\hline
\end{tabular}

Table 4. Experimental Results of Group 3, for $F_{1}=1 / 1$

\begin{tabular}{|c|c|c|c|c|c|c|c|c|c|}
\hline Test No. & $\begin{array}{c}\text { Impact } \\
\text { velocity } \\
\mathrm{V}_{1} \\
(\mathrm{~m} / \mathrm{s})\end{array}$ & $\begin{array}{l}\text { Thickness of } \\
\text { specimen } \\
(\mathrm{mm}) \\
\text { Flyer }\end{array}$ & Target & $\begin{array}{l}\text { Duration } \\
\quad \text { of } \sigma \\
\Delta T \\
(\mu \mathrm{s})\end{array}$ & $\begin{array}{l}\text { Experimental } \\
\text { results }\end{array}$ & $\begin{array}{l}\text { Nominal te } \\
\sigma(\mathrm{MPa}) \\
\text { Prediction } \\
\text { Eqn [6] }\end{array}$ & $\begin{array}{l}\text { sile stress } \\
\text { Error } \\
(\%)\end{array}$ & $\begin{array}{l}\text { Prediction } \\
\text { Eqn [26] }\end{array}$ & $\begin{array}{l}\text { Error } \\
(\%)\end{array}$ \\
\hline $83-11$ & 136.8 & 5.00 & 10.00 & 1.735 & 1153 & 1152 & 0.10 & 1105 & 4.16 \\
\hline $84-112$ & 148.2 & 3.98 & 7.96 & 1.382 & 1251 & 1247 & 0.35 & 1244 & 0.56 \\
\hline $84-73$ & 181.0 & 2.52 & 5.00 & 0.839 & 1536 & 1502 & 2.20 & 1552 & 1.04 \\
\hline $84-87$ & 193.4 & 1.92 & 3.96 & 0.670 & 1645 & 1643 & 0.13 & 1691 & 2.80 \\
\hline
\end{tabular}

Thus, the average damage function $L$ was calculated to be $1.96 \times 10^{5} \mu \mathrm{m} / \mathrm{mm}^{3}, 2.40 \times 10^{5} \mu \mathrm{m} / \mathrm{mm}^{3}$ and $2.77 \times 10^{5} \mu \mathrm{m} / \mathrm{mm}^{3}$ for $F_{1}=1 / 3,1 / 2$ and 1, respectively, with Eqn (26). Therefore, the tensile stresses for each group can be predicted inversely by Eqn (26) with above known $L$ and the duration of tensile stress $\Delta T$. The results were listed in the last column of Tables 2-4. We observed that the results of this paper give better agreement with the experimental data. Additionally, the comparison between criteria and experimental data is showed in Fig. 7.

Now, let us come to Fig. 6 to elucidate that the accumulated damage varies linearly with time at the initial or even intermediate stage of spallation. In fact, the tensile stresses $\sigma$ were around $1.5 \mathrm{GPa}$ and the durations were about $1.0 \mu$ s (see Tables 2-4). Then

$$
\frac{\sigma-\sigma_{0}}{4 \eta} t \leq 10^{-1}
$$

Hence, expansion of the exponential term in the right hand side of Eqn (26) can be ignored for high order terms. Therefore, Eqn (26) can be approximated by

$$
L=c_{0} \dot{N}_{0} \exp \left(\frac{\sigma-\sigma_{0}}{\sigma_{1}}\right) \cdot t
$$




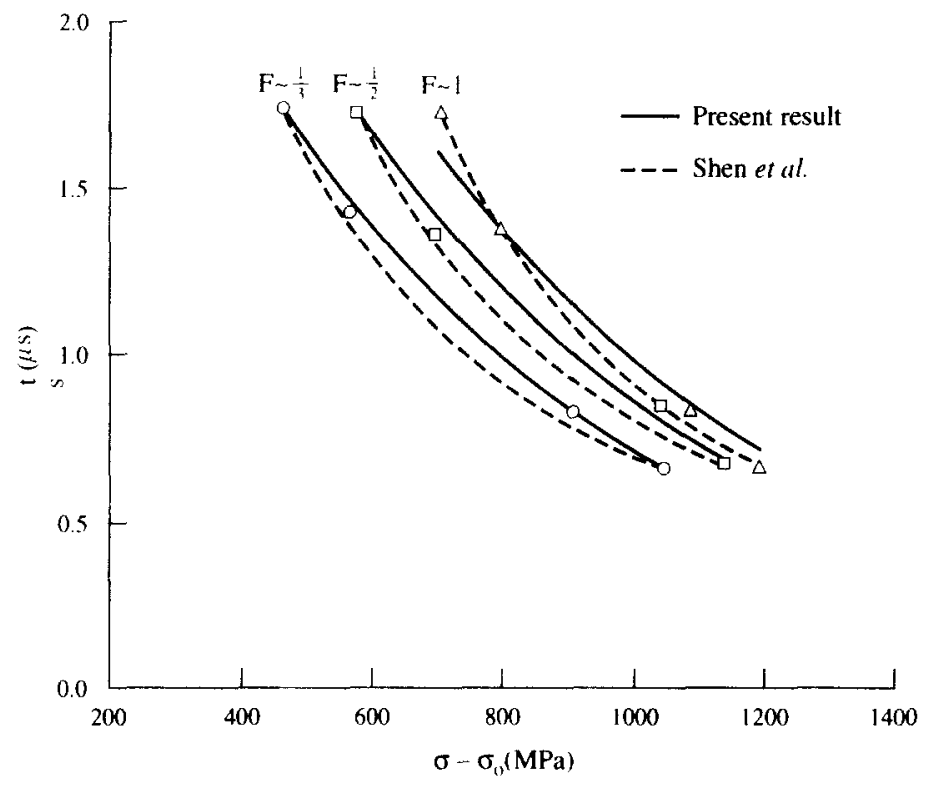

Fig. 7

which gives a linear relation between $L$ and $t$. This linear time dependence seems to be consistent with the empirical criterion of Refs $[8,9]$.

The new damage function $L$ versus the damage function $F_{1}$ was plotted in Fig. 8 . The points present a similar relation between $F_{2}$ and $F_{1}$. This illustrates that the damage function $L$ is a good representation of spall levels and the criterion based on it should be appropriate. Obviously, the criterion requires more material parameters and all the parameters in the criterion have certiain physical meanings. Hence, the model is more realistic than the Tuler-Butcher model. So, using a polynomial form of the Tuler Buther criterion to model the experimental data as well as to approximate the more realistic model Eqn (26) requires two parameters or more. The parameters $\lambda$ and $K^{\prime}$ of Eqn (3) could be understandable in this sense.

It should be pointed out again that Eqn (26) is the result for cases which correspond to ignoring the interaction and coalescence of microcracks. This may be the reason for more deviation from experimental data for group $3\left(F_{1}=1\right)$ shown in Table 4 .

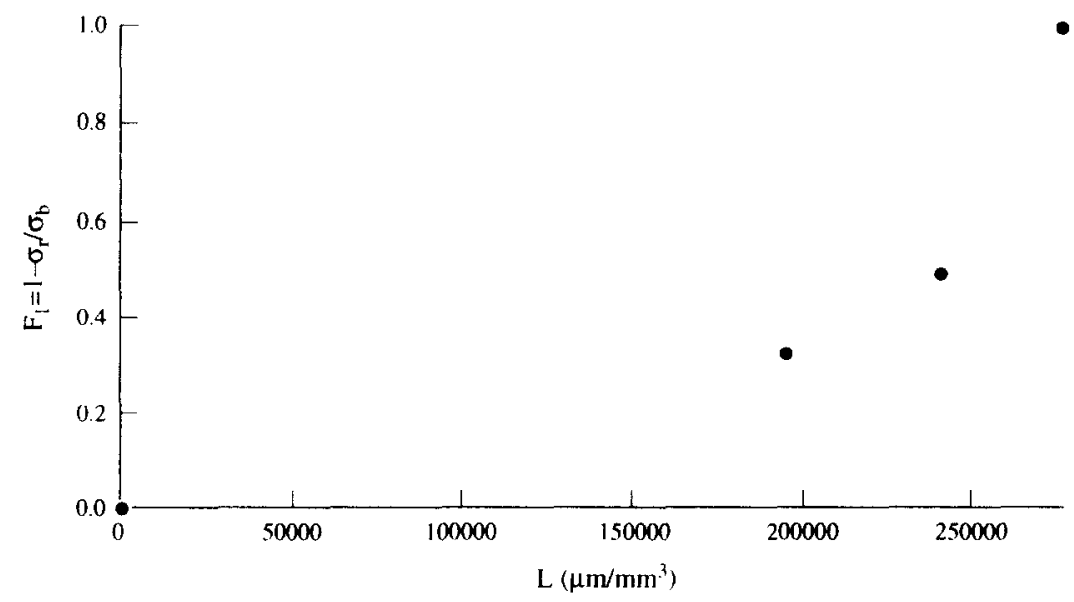

Fig. 8 . 


\section{CONCLUSION}

The present study of spallation criteria has attained the following results by making use of concepts of statistical microdamage mechanics:

(1) A new defined damage function $\left(F_{3}\right)$ and a criterion based on it can properly describe the spallation of an aluminium alloy similar to 2219-T6Al;

(2) More importantly, a greatly simplified method was suggested when neglecting the interaction of damage and the stress variation. The derived criterion has clear physical basis; and

(3) The fitted parameters of the empirical criterion are understandable in the light of the new spallation analysis.

Acknowledgements-The authors are indebted to Professor Mengfen Xia and Professor Fujiu Ke for their valuable help and suggestions in accomplishing this work.

\section{REFERENCES}

1. Hopkinson, B., Brittleness and Ductility, P. 64, Scientific Papers, Cambridge University Press, London (1910).

2. Rinehart, J. S. and Pearson, J., Behaviour of Metals under Impulsive Loads. American Society of Metals, P. 10, 1954, Cleveland, $\mathrm{OH}$.

3. Smith, J. H., Dynamic Behavior of Materials, ASTM, Philadelphia, PA., 264(1963)

4. Butcher, B. M., Barker, L. M., Munson, D. E. and Lundergan, C. D., Influence of stress history on time-dependent spall in metals, AIAA J., 1964, 2, 977.

5. Davison, L. and Stevens, A. L., Continuum measures of spall damage, Journal of Applied Physics, 1972, 43, 988.

6. Davison, L. and Stevens, A. L., Thermomechanical constitution of spalling elastic bodies, Journal of Applied Physics, 1973, 44, 688.

7. Curran, D., Seaman, L. and Shockey, D., Dynamic failure of solids, Physics Reports, 1987, 147, 253.

8. Tuler, F. M., and Butcher, B. M., A criterion for the time dependence of dynamic fracture, International Journal of Fracture Mechanics, 1968, 4, 431

9. Shen, L. T., Zhao, Z. S., Bai, Y. L. and Luo, L. M. Experimental study on the criteria and mechanism of spallation in an aluminium alloy, International Journal of Impact Engineering, 1992, 12, 9.

10. Bai, Y. L., Han, W. S. and Xia, M. F., Statistical formulation and experimental determination of growth rate of micrometre cracks under impact loading. Inst. Mechanics Report: IMCAS STR 94009 (1994).

11. Campbell, J. D., Dynamic plasticity: macroscopic and microscopic aspects, Materials Science Engineering, 1973, 13, 1.

12. Bai, Y. L., Xia, M. F., Ke, F. J., Guo, W. H. and Ling, Z., Statistical interpretation on the relationship between the volumetric and sectional size distributions of disordered mesostructures, Acta Physica Sinica, 1993, 42, 351.

13. Bai, Y. L., Ke, F. J. and Xia, M. F., Formulation of statistical evolution of microcracks in solids, Acta Mech. Simica, 1991,7, 59.

14. Bai, Y. L., Ling, Z., Luo, L. M. and Ke, F. J., Initial development of microdamage under impact loading, Journal of Applied Mechanics, 1992, 59, 622 .

15. Schiel, Z., Die berechnung der anzahl und groBenverteilung kugelformiger kristalle in undurchsichtigen korpern mit hilfe der durch einen ebenen schnitt erhaltenen schnittkreise, Zeitschrift fur Anorganische und Allgemeine Chemie, 1931, $201,259$.

16. Schiel, Z., Statistische gefugeuntersu chungen I, Zeitschrift fur metallkunde, 199.

17. Underwood, E. E., Stereology and Quantitative Metallography. G. E. Pellissier and S. M. Purdy, Eds, Cochairmen, American Society for Testing and Materials, 1972.

\section{APPENDIX A}

The derivation of Eqn (13)

The derivation of the fundamental integral equation governing the transformation of sectional observations of meso-structures to their volumetric size distribution is based upon the following assumptions:

(1) The concerned mesoscopic structures have the simplest configuration, namely spheres or parallel penny-shaped cracks.

(2) The spheres and penny-shaped cracks are homogeneously, radomly distributed in the material.

It worth noting that no limitaton has been imposed on the form of size distribution. First, we define the following quantities to describe the size distribution of these meso-structures:

$c$-length scale of meso-structures, i.e. the true diameter of sphere or penny-shaped cracks;

$c^{\prime}$-apparent length scale of meso-structures on sectional surface, i.e. the diameter of the apparent 
circle of sphere or the length of the apparent crack line of penny-shaped crack on sectional surface

$n(c)$-volumetric number density of the meso-structures. For instance, $n(c) \mathrm{d} c$ represents the number of spheres in unit physical volume and in the interval of sphere-diameter $c-c+\mathrm{d} c$; and

$m\left(c^{\prime}\right)$-/Sectional number density of the meso-structures. For instance, $m\left(c^{\prime}\right) \mathrm{d} c^{\prime}$ represents the number of apparent circles of spheres, which are sectioned and show themselves as circles with diameter ranging $c^{\prime}-c^{\prime}+\mathrm{d} c^{\prime}$ in unit physical area on the sectional surface.

To determine the number of cracks or voids within a given size range, say from $c_{i}^{\prime}$ to $c_{i+1}^{\prime}$, and $c_{j}$ to $c_{j+1}$, we form the integrals

$$
M_{\mathrm{i}}\left(c^{\prime}\right)=\int_{c_{i}}^{c_{i}} m\left(c^{\prime}\right) \mathrm{d} c^{\prime}
$$

and

$$
N(c)=\int_{c}^{c} n(c) \mathrm{d} c
$$

Thus we see that the units for $m\left(c^{\prime}\right)$ and $n(c)$ are $[$ number $] /[\text { length }]^{3}$ and $[$ number $] /[\text { length }]^{4}$.

The basic idea of the derivation of the equation governing the transformation is due to previous works [15-17] and can be explained as follows. In the case of spheres, the observed number $m\left(c^{\prime}\right) \mathrm{d} c^{\prime}$ of circles on sectioned surface in the interval of diameter $c^{\prime} c^{\prime}+\mathrm{d} c^{\prime}$ is attributed to the spheres, which have diameters greater than $c^{\prime}$ and are sectioned in the concerned volume. Furthermore, for an assigned sphere, its probability to be sectioned to become circles with diameter $c$ between 0 and $c$ can be determined according to equal probability of circles with the same increment in its height. In order to sketch the idea clearly, a penny-shaped crack and its sectional line are shown in Fig. 9. It can be verified that the case of spheres follows the same procedure, reasoning and result.

For a penny-shaped crack with diameter, $c=2 R$, its probability $p\left(c^{\prime}\right) \mathrm{d} c^{\prime}$ showing a crack line with a length in $c^{\prime}-c^{\prime}+\mathrm{d} c^{\prime}$ on a sectional surface is

due to

$$
p\left(c^{\prime}, c\right) \mathrm{d} c=-\frac{\mathrm{d} r}{R}=\frac{1}{c} \frac{c^{\prime} \mathrm{d} c^{\prime}}{\sqrt{c^{2}-c^{\prime 2}}}
$$

$$
r^{2}=R^{2}-\left(c^{\prime} / 2\right)^{2} \text { and } \mathrm{d} r=-\frac{c^{\prime} \mathrm{d} c^{\prime}}{2 \sqrt{c^{2}-c^{\prime 2}}}
$$
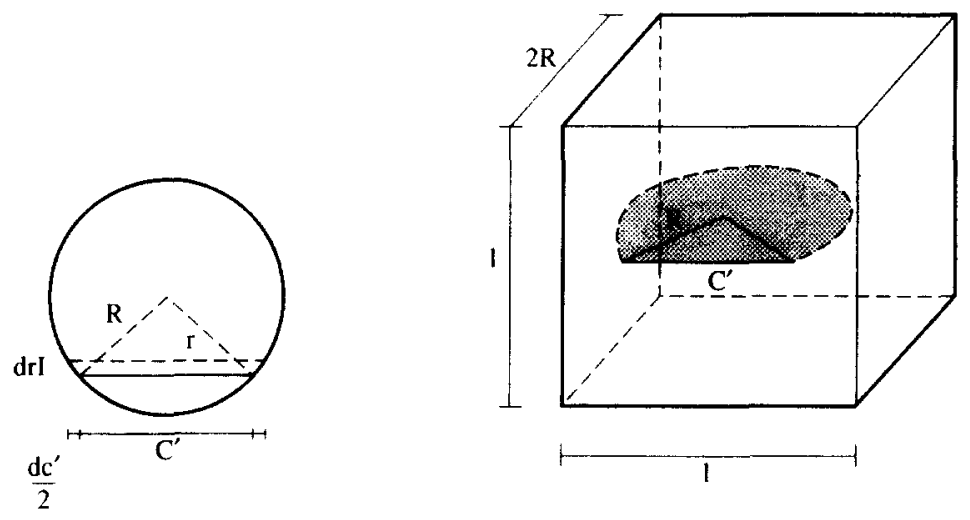
If each crack is represented by its mass center, then the number of cracks with diameters between $c-c+\mathrm{d} c$ in a given volume $c \cdot l^{2}$ (see Fig. 9) is

$$
\begin{aligned}
m\left(c^{\prime}\right) \mathrm{d} c^{\prime} \cdot l^{2} & =\int_{c=c}^{\infty} n(c) \mathrm{d} c \cdot c \cdot l^{2} \cdot p\left(c^{\prime}, c\right) \mathrm{d} c^{\prime} \\
& =\int_{c=c}^{\infty} n(c) \mathrm{d} c \cdot c \cdot l^{2} \cdot \frac{1}{c} \frac{c^{\prime} \mathrm{d} c^{\prime}}{\sqrt{c^{2}-c^{\prime 2}}} .
\end{aligned}
$$

The integral is due to the contribution made by all the penny-shaped cracks with diameter greater than $c^{\prime}$ and corresponding probability $p\left(c^{\prime}\right) \mathrm{d} c^{\prime}$, now, the governing integral equation can be written as follows:

$$
\frac{m\left(c^{\prime}\right)}{c^{\prime}}=\int_{c^{\prime}}^{\infty} n(c) \frac{\mathrm{d} c}{\sqrt{c^{2}-c^{\prime 2}}}
$$

where $m\left(c^{\prime}\right)$ is the observed quantity on the sectional surface, and $n(c)$ is the unknown volumetric size distribution. Obviously, this is a first-kind Volterra's integral equation but with infinite integral limit and singular kernel.

\section{APPENDIX B}

The derivation of Eqn (14) [the solution to Eqn (A.3)]

Usually, the function $m\left(c^{\prime}\right)$ is generally normal in practice. Noticeably, the kernel $1 / \sqrt{c^{2}-c^{\prime 2}}$ is continuous and differential in the range $\left(c^{\prime}, \infty\right)$, but with $(-1 / 2)$ power signularity at lower integral limit $c=c^{\prime}$. This shows apparent similarity to the Abel's integral equation.

To solve the integral equation, we multiply Eqn (A.3) by $1 / \sqrt{c^{\prime 2}-2}$, and then integrate it with respect to $c^{\prime}$ between the limits $c^{\prime}=\mathrm{z}$ and $c^{\prime}=\infty$ :

$$
\int_{z}^{\infty} m\left(c^{\prime}\right) \frac{\mathrm{d} c^{\prime}}{\sqrt{c^{\prime 2}-z^{2}}}=\int_{z}^{\infty} c^{\prime} \frac{\mathrm{d} c^{\prime}}{\sqrt{c^{\prime 2}-z^{2}}} \int_{c^{\prime}}^{\infty} n(c) \frac{\mathrm{d} c}{\sqrt{c^{2}-c^{\prime 2}}}
$$

where $z$ is an intermediate variable, an alternative representation of length scale, either $c$ or $c^{\prime}$. The integral region of the double integral in the right hand side of Eqn (B.1) is the shaded angular domain in the $\grave{c}-c^{\prime}$ plane, as shown in Fig. 10. When we exchange the order of the double integral, expression

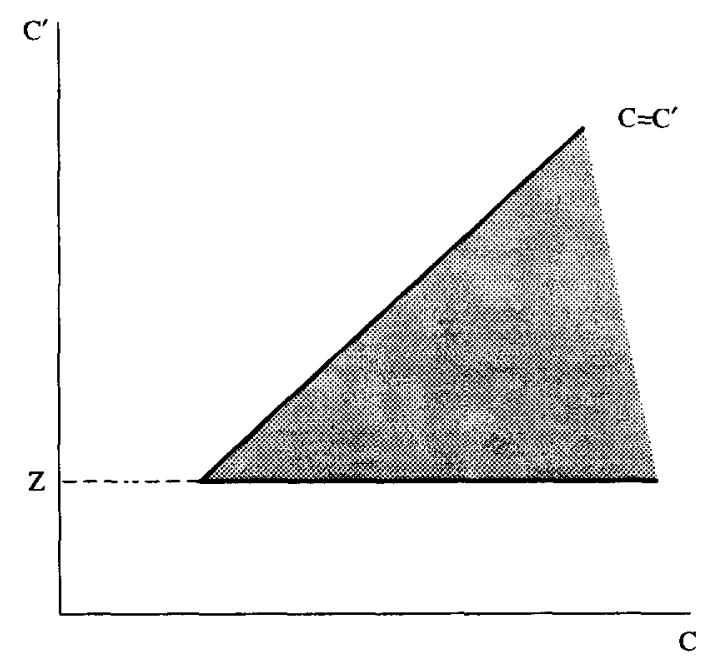

Fig. 10 
(B.1) should be rewritten with correspondingly changed integral limits as follows

$$
\int_{=} \frac{m\left(c^{\prime}\right)}{\sqrt{c^{\prime 2}-\mathrm{z}^{2}}} \mathrm{~d} c^{\prime}=\int_{=}^{\prime} n(c) \mathrm{d} c \int_{z}^{c} \frac{c^{\prime} \mathrm{d} c^{\prime}}{\sqrt{\left(c^{2}-c^{\prime 2}\right)\left(c^{\prime 2}-z^{2}\right)}}
$$

let $t=\frac{c^{2}-c^{2}}{c^{2}-z^{2}}$, we can obtain

$$
\int \frac{c d c}{\sqrt{\left(c^{2}-c^{\prime 2}\right)\left(c^{\prime 2}-z^{2}\right.}}=\frac{1}{2} \int_{0}^{1} \frac{\mathrm{d} t}{\sqrt{t(1-t)}}=\frac{\pi}{2}
$$

thus

$$
N(z)=\int_{=}^{\prime} n(c) \mathrm{d} c^{\prime}=\frac{2}{\pi} \int_{z}^{\prime} \frac{m\left(c^{\prime}\right)}{\sqrt{\mathrm{c}^{\prime 2}-\mathrm{z}^{2}}} \mathrm{~d} c^{\prime}
$$

where $N(z)$ is the cumulative number density of penny-shaped cracks with diameters not less than $z$ in per unit volume. In order to calculate the following differentiation

$$
n(z)=-\frac{\mathrm{d} N(z)}{\mathrm{d} z}=-\frac{2 \mathrm{~d}}{\pi \mathrm{d} z} \int_{z}^{\prime} \frac{m\left(c^{\prime}\right)}{\sqrt{\mathrm{c}^{\prime 2}-\mathrm{z}^{2}}} \mathrm{~d} c^{\prime}
$$

we notice

$$
\frac{\mathrm{d} c^{\prime}}{\sqrt{\mathrm{c}^{\prime 2}-\mathrm{z}^{2}}}=\frac{1}{c^{\prime}} \mathrm{d}\left(\sqrt{\mathrm{c}^{2}-\mathrm{z}^{2}}\right)
$$

and then integrate by part, thus,

$$
n(z)=\frac{2}{\pi} \int_{=}^{\prime} \frac{z}{\sqrt{c^{\prime 2}-z^{2}}}\left[-\frac{1}{c^{\prime}} \frac{\mathrm{d} m\left(c^{\prime}\right)}{\mathrm{d} c^{\prime}}+\frac{m\left(c^{\prime}\right)}{c^{\prime 2}}\right] \mathrm{d} c^{\prime} .
$$

In the derivation, we have used the apparent boundary condition $\lim _{c^{\prime} \rightarrow x} m\left(c^{\prime}\right)=0$. 